\title{
An Empirical Research on the Effect of Low-Carbon Knowledge of the Urban Residents on their Low- Corbonized Energy Consumption Behavior
}

\author{
Lingyun Mi \\ China University of Mining and Technology \\ Rui Nie \\ China University of Mining and Technology
}

\begin{abstract}
Based on the literature research, this article classifies Low Carbon Knowledge into system knowledge, action knowledge and effectiveness knowledge. Then by introducing two variables of "Behavior Intention" and "behavior competence", we build a conceptual model about various effects of Low Carbon Knowledge on lowcarbonized energy consumption behavior. We investigate the residents in 49 cities in China and get 4129 valid samples. We use LISREL 8.7 for parameter estimation, and modify the model by $\mathrm{T}$ test. The result shows that "system knowledge" and "action knowledge" mainly affects consumption behavior through Behavior Intention, and "effectiveness knowledge" mainly affects consumption behavior through behavior competence. Buying behavior is more influenced by Behavior Intention, and using behavior is more influenced by behavior competence. Therefore, the result of this paper improves the pertinence and effectiveness of spreading Low Carbon Knowledge, and then we can effectively guide urban residential energy consumption behavior in the low-carbon direction.
\end{abstract}

Keyword: Low-carbon Knowledge, urban residents, low-carbonized, Energy consumption behavior

\section{Introduction}

Low carbonization has become the general trend in the global economic development. In terms of the structure of urban and rural distribution in China, per capita energy consumption of the urban residents is $2 \sim 3$ times as much as that of the rural residents (National Bureau of Statistics of the People's Republic of China, 2010). At present urban residents is the main body of household energy consumption in China. At the same time, China is now on a stage of accelerated urbanization development, 
and population urbanization rate increases by $1 \%$ every year. Therefore, energy consumption of the urban resident, low carbonized or not, has not only a direct effect on the total energy consumption structure, residents scale and growth rate, but also an indirect impact on the value judgment and choice of industrial products. When urban residents' low-carbonized energy consumption behavior becomes the established social norms, it will promote low carbonization in the fields of production and circulation, and boost the realization of the goals of energy and emission reduction in China from the viewpoints of demand management.

Urban residents' low-carbonized energy consumption behavior belongs to residents' positive environment behavior. Existing researches consistently show that environmental knowledge is an important factor on environmental behavior. Hines selected 380 articles related to environmental behavior, and used meta analysis to integrate 128 articles about environmental behavior and its influencing factors, and then put forward the famous idea of responsible environmental behavior model. The model pointed out that action strategy knowledge and environmental knowledge are important factors affecting responsible environmental behavior (Hines, 1986). After this, Simmons and Grunert's studies supported Hines's view (Simmons,1990, Grunert,1993). Simmons pointed out that a lack of knowledge is a substantial obstacle to people who had a positive attitude towards protecting environment. It shows that in order to cultivate and guide urban residents' low-cabonized energy consumption behavior, it is necessary for the residents to acquire some Low Carbon Knowledge.

Because of the different views of existing researches on the classification of environmental knowledge, there are a lot of disputes over the effect of environmental knowledge on environmental behavior. Schahn J studied the living waste management behavior of German residents and confirmed that specific environmental knowledge had significant effect on environmental behavior, but general environmental knowledge's influence is very small(Schahn J ,1990). Carmen Tanner,\& Kast studied the Swiss consumers and found that procedural knowledge can significantly affect green buying behavior, and stating knowledge has no effect(Carmen Tanner,,2003). Michele thought that environmental knowledge about fact can significantly affect green buying behavior, and general environmental knowledge has no effect (Michele T, 2004). Ricky Y K Chan studied Beijing and Guangzhou consumers and found that the stating environmental knowledge, through green buying intention, has a significant positive impact on general green buying behavior (Ricky Y K Chan, 2001).

As environmental problems caused by fossil energy consumption are getting increasingly serious, researchers began to focus on the influence of energy knowledge on household energy use behaviors. Stern, Staats and Harland's researches found that knowledge of energy utilization can affect green energy buying and using behavior (Stern 1992, Staats, 2000, Harland, 2007). Parker and Linda Steg's studies on household energy saving found that a lack of knowledge of energy use is one of the major obstacles to implementing household energy saving (Parker P, 2005, Linda Steg, 2008). Lishun Chen took the residents in Dalian as the object of his empirical study and confirmed that energy knowledge has a significantly positive effect on behavior (Lishun Chen, 2009). However, these studies have not classified energy 
knowledge, so we are not sure which kind of knowledge can have the positive effect on behavior. We are also not sure whether different types of knowledge can result in a significant difference in the residents' energy use behaviors. These lead to a lack of target and pertinence in promoting environmental knowledge.

Therefore, on the basis of realizing Low Carbon Knowledge's influence on residential low-cabonized energy consumption behavior, it will be the key to guide residents' behavior that we study the influence mechanism and effect of different types of low carbon knowledge on low-cabonized energy consumption behavior. To this end, this paper borrows Jacqueline Frick's classification of environmental knowledge that divides Low Carbon Knowledge into System Knowledge, Action Knowledge and Effectiveness Knowledge, and adopts the empirical method to inspect the influence mechanism and the effect of three kinds of low carbon knowledge (Jacqueline Frick, 2004). In this way we can provide reference and basis to guide the urban residents to form low-cabonized energy consumption behavior though knowledge.

\section{Literature Review and Research Hypothesis}

\section{Concept and Definition of Low-cabonized Energy Consumption Behavior}

The main cause of global warming is $\mathrm{CO} 2$ emission from the consumption of fossil energy, which happens to take a major part in China and the world's energy structure. Therefore, residents' reduction in $\mathrm{CO} 2$ emission behavior is closely related to residents' energy consumption behavior. In the existing literature, residential energy consumption behavior is defined in the perspective of the performance of residential energy consumption behavior. It often overlaps the concepts of Household Energy Use, Residents' Energy Conservation Behavior and so on. Van Raaij defined residential energy use as the consumption behavior related to buying, maintaining and using energy (Van Raaij,1983). Van Diepen defined household energy use as home energy use and transport energy use (Van Diepen,2000). Scott thought that domestic energy behavior is composed of investment, management and curtailment (Scott. D, 2000), Anna-Lisa Linden surveyed and interviewed 600 Swedish households and defined residential energy behavior as energy use in five aspects ---heating, lighting, cleaning, food supply, entertainment and information (Anna-Lisa Linden, 2006). By summarizing the existing literature, Stewart Barr defined residential conservation behaviors as habit--related conservation behaviors and purchase-related conservation behaviors (Stewart Barr, 2005). Lishun Chen defined urban residential energy consumption behavior as "all sorts of energy use and consumer behavior of the urban residents", including selective energy consumption behavior and habitual energy consumption behavior (Lishun Chen, 2009).

With a reference to the definitions of the residential energy behavior mentioned above, this paper defines residential "low-cabonized energy consumption behavior" as "energy consumption behavior that aims at the goal of $\mathrm{CO} 2$ reduction and takes the forms of the buying behavior for energy saving products, green energy and energy saving facilities, and the using behavior for energy consumption equipments and facilities in daily life". This definition has two dimensions: Buying behavior and 
using behavior. In the Chinese urban areas, low-carbonized buying behavior that an individual can adopt is buying energy-efficient appliances behavior (BEAB), buying green energy behavior (BGEB) and residential energy saving investment behavior (REIB). Using behavior (UB) refers to residential active management behavior for energy consumption volume and energy use efficiency of the purchased equipment. It includes saving behavior and improving energy efficiency behavior. Buying behavior has the characteristics of being disposable, relatively rational and investable. Using behavior has the characteristics of repeatability, bounded rationality and being habitual.

\section{Classification of Low Carbon Knowledge}

Knowledge is a mixture of information, experience and opinions achieved by an interaction between individual and environment. Since Knowledge is a relatively broad concept, its definition varies from one discipline to another. Knowledge related to residential low-cabonized energy consumption behavior is low carbon knowledge, which belongs to the category of environmental knowledge. Therefore, this paper defines Low Carbon Knowledge as a mixture of information, experience and opinions concerning $\mathrm{CO} 2$ emission cut.

Low carbon knowledge falls into the category of environmental knowledge, which can be explained both in a broad sense and in a narrow sense. The broad sense of environmental knowledge contains procedural knowledge, stating knowledge, general knowledge and specific knowledge, etc. The narrow sense of environmental knowledge is classified according to the specific environmental issues. Marcinkowski divided environmental knowledge into natural environmental knowledge, environmental problem knowledge and environmental action knowledge (Marcinkowski T. J, 1988). In his study of environmental protection actions, Jacqueline Frick divided environmental knowledge into system knowledge, actionrelated knowledge and effectiveness knowledge. System knowledge refers to an individual's basic understanding of environmental system and ecological process. It is the knowledge concerning "what you know". Action-related knowledge refers to behavior choice and usual practice. It is the knowledge of "knowing how to do". Effectiveness knowledge refers to an understanding of the consequence of behavior. It is knowledge concerning "which kind of knowledge is more effective" (Jacqueline Frick, 2004). Frick's classification is widely recognized in the study of environmental behaviors.

This research borrows Jacqueline Frick's classification and divides Low Carbon Knowledge into system knowledge (SK), action knowledge (AK) and effectiveness knowledge (EK). System knowledge refers to the basic understanding the residents hold towards carbon emissions and low carbon development, such as what is the greenhouse effect? Action knowledge refers to the usual practice of the residential low carbon behavior, such as reducing fuel automobile use, reducing power consumption and turning off the air conditioning can reduce $\mathrm{CO} 2$ emissions. Effectiveness knowledge refers to a realization of the difference in carbon emission among various energy consumption behaviors, such as radiant floor heating is more effective than convection heating. 


\section{Research Hypothesis}

Hines' responsible environmental behavior model established in the method of metaanalysis is one of the representative researches in the effect of environmental knowledge on positive environmental behavior. Hines pointed out that responsible environmental behavior is the result of Behavior Intention, which in turn is influenced by individual knowledge and skills. Environmental knowledge and behavior strategy knowledge have an indirect but significant positive effect on behavior through Behavior Intention (Hines, 1986). His viewpoints are supported by Simmons' study on Environmental protection behavior and Grunert's study on green food buying behavior (Simmons, D, 1990, Grunert, S. C, 1993). Ricky Y K Chan studied Beijing and Guangzhou consumers and found that environmental knowledge has a significant and positive effect on green buying behavior through the variables of green buying intention or environmental emotion (Ricky Y K Chan, 2001). Yan Sun divided the residents' environmental behavior into Ecological management behavior, consumer behavior, persuasion behavior and civil behavior. The results showed that environmental knowledge has a significant predictive power for the four types of environmental behavior through the attitude variables (Yan Sun, 2006).

In addition, Stern, Staats and Harland's researches on buying and using behavior of green energy, Parker, Linda Steg and Lishun Chen's researches on household energy use behavior all found that the knowledge of energy use is an important factor affecting the residents' energy behavior (Stern, 1992, Staats,2000, Harland, 2007 ,Parker, 2005, Linda Steg, 2008, Lishun Chen', 2009).

In his classical Plan Act Theory, Ajzen pointed out that Behavior Intention (BI) is the most direct dependent variable to influence behavior, and other subjective psychological factors affect behavior indirectly through Behavior Intention. Behavior Intention refers to psychological tendency and motives before action. It reflects that a person's willingness to spend his time and effort to carry out this behavior (Ajzen, 1991). In Kara Chen's study of the wastes behavior of Hong Kong residents, Kaise's study of the environmental behavior of Swiss residents, Satoshi's study of the environmental behavior of Tokyo family, Khalil's study of the environmental behavior of Iran Deheran residents, it is confirmed that Behavior Intention is the direct dependent variable to influence environmental behavior, and other subjective psychological factors affect environmental behavior indirectly through Behavior Intention. (Kara Chen, 1998, Kaise,1999, Satoshi F, 2006, Khalil, 2007)

On the basis of the views mentioned above, we make Hypothesis 1:

Hypothesis 1: Low-carbon Knowledge (LCK) may have an indirect and positive effect on Low-cabonized Eenergy Consumption Behavior through Behavior Intention (BI)

Hypothesis 1a: SK may have a direct and positive effect on BI

Hypothesis 1b: AK may have a direct and positive effect on BI

Hypothesis 1c: EK may have a direct and positive effect on BI

Hypothesis 1d: BI may have a direct and positive effect on BEAB

Hypothesis 1e: BI may have a direct and positive effect on BGEB

Hypothesis 1f: BI may have a direct and positive effect on REIB 
Hypothesis 1g: BI may have a direct and positive effect on UB

In his theory of planned behavior, Ajzen emphasized that Behavior Intention is the direct dependent variable of behavior. He also pointed out an important premise for Behavior Intention to predict behavior. That is, behavior that can be completely controlled by an individual will be directly determined by Behavior Intention; behavior that can't be completely controlled by an individual will not only be directly determined by Behavior Intention, but also be determined by personal ability, opportunities and resources. Only in the event that these conditions can be controlled can Behavior Intention directly determine behavior (Ajzen, 1991). But in the real case this state is relatively scarce. As to the urban residential low-cabonized energy consumption behavior, neither buying behavior nor using behavior can be completely controlled by individual wills. For example, because of a lack of ability, an individual with high intentions will not achieve a low carbon behavior target. Thomas L. Webb used Meta-analysis to research specific behavior and found that correlation between Behavior Intention and behavior is a very big variable. Only when they show a strong control ability to behavior will people tend to act on their will (Thomas L. Webb, 2006). Therefore, there are undoubtedly limitations of explanatory power when we simply predict low-carbonized energy consumption behavior though low carbon Behavior Intention.

Behavioral research suggests that an effective completion of a campaign is a joint result of motivation and competence. Motivation reflects the extent to which an individual is willing to implement a behavior. It's a symbol of subjective intention. Competence reflects the possibility that an individual is able to implement a behavior. To achieve a desired goal, the "willingness" to do well is not enough. People also need to have the "ability" to do well. Therefore, the concept of "low carbon behavior competence" is introduced into this paper.

Stephen P. Robbins pointed out that "competence" reflects the possibility that an individual implements a variety of tasks in some work. It's a realistic assessment of what an individual can do. Because of the differences in individual competence, the same efforts will often bring about different results of behavior (Stephen, 1997). Residents' low-cabonized energy consumption behavior aims to reduce emissions of $\mathrm{CO} 2$. It not only expects the residents to have low carbon Behavior Intention, but also requires the residents to have low carbon behavior competence. So this paper introduces the concept of "low carbon behavior competence". We regard Behavior Competence as the possibility of a target individual to complete a task or implement a behavior. Low carbon Behavior Competence means the possibility of an individual to complete a low carbon task or reduce $\mathrm{CO} 2$ emissions. This Behavior Competence means that the actor is qualified for the target action and is capable of achieving an excellent performance.

Individual behavior competence is a kind of external performance of knowledge. It enables an individual to achieve efficiency and effectiveness in his activities. Therefore, this paper regards "low carbon behavior competence" and "low carbon Behavior Intention" as the mediators between low carbon knowledge and lowcabonized energy consumption behavior. Then we make Hypothesis 2: 
Hypothesis 2: Low-carbon Knowledge may have an indirect and positive effect on low-cabonized energy consumption behavior through Behavior Competence (BC)

Hypothesis 2a: SK may have a direct and positive effect on $B C$ Hypothesis 2b: AK may have a direct and positive effect on $B C$ Hypothesis 2d: BC may have a direct and positive effect on $B E A B$ Hypothesis 2e: BC may have a direct and positive effect on BGEB Hypothesis 2f: BC may have a direct and positive effect on REIB Hypothesis 2g: BC may have a direct and positive effect on $U B$

\section{Conceptual Model}

Based on the literature review and hypothesis, this paper builds a conceptual model about the effects of various Low-carbon Knowledge on low-carbonized energy consumption behavior is shown in Figure 1.

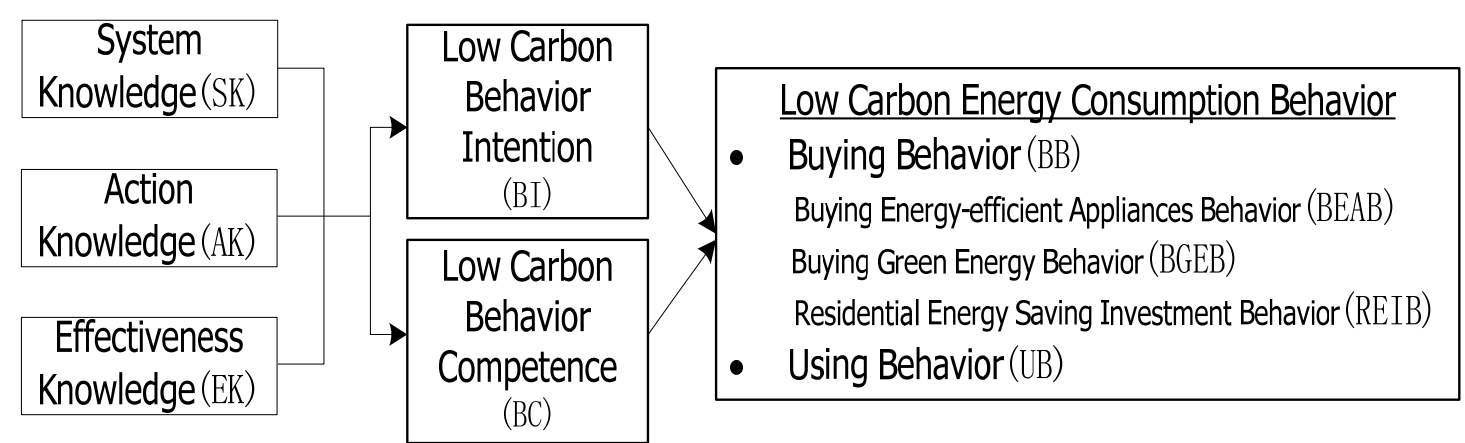

Figure 1: Conceptual Model

\section{Research Design and Data Quality Control}

\section{Scale Development}

This study adopts Likert scale and the questionnaire contains 36 items. As to the measurement of "low carbon knowledge" (LCRK), we refer to Frick and Kaiser's research, and divide knowledge into system knowledge (SK), action knowledge (AK) and effectiveness knowledge (EK). Each knowledge type has three measurement indexes, and involves nine questions. Measurement of "Low carbon Behavior Intention" refers to Chan's scale and Stern's and Pieters' researches, and involves five measurement indexes (Chan R.Y.K, 2001, Stern P.C, 1999, Pieters, 1991). We design our own measurement of "Low carbon behavior competence" and set up four indexes. The measurement of "Low-cabonized energy consumption behavior" is divided into the two aspects of buying behavior and using behavior. It gives reference to Linden A.-L.'s scale, Notice on the Strict Implementation of Public Buildings Air Conditioning Temperature Control Standard compiled in 2007 by the General Office of the State Council of P.R.C.(The State Council of the People's Republic of China, 2007), Manual of National Energy Conservation And Emission Reduction issued by Ministry of Science and Technology of P.R.C.in 2007(The Ministry of Science and 
Technology of the People's Republic of China, 2007), Xianfeng Zhang's A Reading Collection of Low Carbon Life Knowledge (Xianfeng Zhang, 2010), and Zhi Yang's Open The Window Of Low Carbon Economy (Zhi Yang, 2010). Buying behavior is divided into buying energy-efficient appliances (BEAB), buying green energy (BGEB) and residential energy saving investment (REIB) and involves nine measurement indexes. Using behavior involves 10 measurement indexes, which are concerned with the prevailing energy use behavior in the daily life of Chinese urban residents.

\section{Initial Investigation and Formal Investigation}

This questionnaire of study contains initial investigation and formal investigation. The respondents of the initial survey are residents of Xuzhou, China, who were selected by means of friend relationship and random interviews in residential area and business place. This survey issued 350 copies of questionnaire, and collected 212 copies of valid reply. SPSS 17.0 was used to test its reliability and validity. Cronbach's Alpha Coefficient proposed by Wortzel in 1971 was used to test the reliability. Results show that when we delete U8, Cronbach's alpha coefficients of four scales reach more than 0.6 . This explains that the scale has good reliability. The scale is valid with its "Item-to-total" larger than 0.3 and the "Alpha" of each factor larger than 0.6 .

The research objects are urban residents. While China is a large country, its level of economic and social development varies from region to region, and city to city. Therefore, the data were collected by means of sample survey from all regions and all cities. This research gives priority to paper questionnaire survey, supplemented by Email survey, in order that the questionnaire should involve all the three economic zones (the east, the middle and the west) and the four levels of cities in China, and that the samples should be typical and the answers should be reliable. We distributed the paper questionnaire in kindergartens, primary and secondary schools, and communities, and in this way completed the investigation of the parents and local residents. In addition, we send E-mail from acquaintances to acquaintances to make the survey available to more residents of the city. The total of the questionnaires is 6259 copies, and the valid questionnaires are 4129 copies, so the questionnaire efficiency reaches $82.05 \%$. Valid questionnaires cover 49 cities. As to the locations of the surveyed cities, 31 of them are in the eastern economic region, 13 in the central economic region and 5 in the western economic region. As to the economic and social development levels of these cities, there are 5 first-level cities, 21 second-level cities, 14 third-level cities and 9 forth-level cities. Table 1 shows the descriptive statistics of the valid samples. Their regional distribution and residential composition are representative of the Chinese urban residents. 
Table 1: Valid Sample Descriptive Statistics

\begin{tabular}{llll}
\hline Items & Options & Frequency & Percentage \\
\hline \multirow{2}{*}{ Gender } & Male & 2011 & $48.7 \%$ \\
& Female & 2118 & $51.3 \%$ \\
\hline \multirow{5}{*}{ Age } & Under 20 & 336 & $8.1 \%$ \\
& $21-30$ & 970 & $23.5 \%$ \\
& $31-40$ & 1492 & $36.1 \%$ \\
& $41-50$ & 1001 & $24.2 \%$ \\
& $51-60$ & 209 & $5.1 \%$ \\
& Over 60 & 121 & $2.9 \%$ \\
\hline \multirow{5}{*}{ Education } & Junior middle school and below & 610 & $14.8 \%$ \\
& Senior middle school & 1260 & $30.5 \%$ \\
& university & 1857 & $45.0 \%$ \\
& Master or doctor & 402 & $9.7 \%$ \\
\hline \multirow{5}{*}{ Occupation } & Yes & 2976 & $72.1 \%$ \\
& No & 1153 & $27.9 \%$ \\
\hline & The government department staff & 280 & $6.8 \%$ \\
& Common workers or service personnel & 1041 & $25.2 \%$ \\
& Corporate executives & 590 & $14.3 \%$ \\
& environmental health workers & 367 & $8.9 \%$ \\
& Private employer & 456 & $11.0 \%$ \\
& Retirement or family women & 422 & $10.2 \%$ \\
& Others r reseation & 258 & $6.2 \%$ \\
& & 715 & $17.3 \%$ \\
\hline
\end{tabular}

(1) Validity Analysis

SPSS 17.0 was used to do EFA. The bigger the value of KMO indicators is, the more suitable the data are for factor analysis. Normally, the value must be more than 0.7 . In this survey, the value of KMO is 0.927 and Bartlett's Test is 0.000 . We used principal component factor analysis method and sort the items in 9 factors. Explained rate of variance is $64.766 \%$. We adopted variance most money-raising orthogonal rotating. Result shows that the load of every item in their respective factor are more than 0.5 and the load of every items in other factors are less than 0.5. The analysis results indicates that the scale has good convergent validity and discriminate validity, as is shown in Table 2. 
Table 2: Exploratory Factor Analysis of Initial Data

\begin{tabular}{|c|c|c|c|c|c|c|c|c|c|}
\hline \multirow{2}{*}{ Items } & \multicolumn{9}{|c|}{ Component } \\
\hline & 1 & 2 & 3 & 4 & 5 & 6 & 7 & 8 & 9 \\
\hline B1 & .130 & -.018 & .195 & .775 & .037 & .053 & .165 & .014 & .027 \\
\hline B2 & .162 & .034 & .201 & .792 & .032 & -.009 & .170 & .164 & .025 \\
\hline B3 & .134 & .034 & .228 & .758 & .029 & .000 & .172 & .119 & .008 \\
\hline B4 & .156 & .036 & .139 & .388 & .072 & -.021 & .161 & .609 & .179 \\
\hline B5 & .230 & .044 & .115 & .037 & .155 & .042 & .435 & .605 & -.038 \\
\hline B6 & .130 & .126 & .157 & .161 & .055 & .033 & .656 & .323 & -.173 \\
\hline B7 & .175 & .050 & .186 & .259 & .056 & .027 & .742 & .066 & .058 \\
\hline B8 & .177 & .042 & .125 & .410 & .035 & .089 & .611 & .019 & .117 \\
\hline U1 & .581 & .025 & .140 & .350 & .074 & .111 & .112 & -.165 & .031 \\
\hline U2 & .668 & .050 & .120 & .361 & .056 & .092 & .034 & -.090 & -.058 \\
\hline U3 & .590 & .077 & .075 & .240 & .074 & -.070 & -.010 & .357 & -.104 \\
\hline U4 & .570 & .069 & .064 & .036 & -.022 & .148 & .044 & .226 & .069 \\
\hline U5 & .683 & .134 & .055 & .034 & .194 & -.012 & .082 & .160 & -.194 \\
\hline U6 & .695 & .124 & .110 & .007 & .140 & -.008 & .265 & -.136 & .064 \\
\hline U7 & .717 & .107 & .096 & .066 & .144 & .005 & .017 & .111 & .115 \\
\hline U9 & .480 & .017 & .139 & .071 & .034 & .110 & -.022 & .178 & .534 \\
\hline U10 & .647 & .133 & .117 & -.035 & .217 & .017 & .194 & .026 & .202 \\
\hline BI1 & .162 & .054 & .745 & .177 & .072 & .157 & -.006 & .083 & .019 \\
\hline $\mathrm{BI} 2$ & .096 & .098 & .802 & .136 & .094 & .089 & .109 & .045 & -.059 \\
\hline $\mathrm{BI} 3$ & .165 & .100 & .731 & .112 & .145 & .112 & .076 & .128 & -.144 \\
\hline BI4 & .111 & .164 & .729 & .170 & .092 & -.033 & .138 & -.021 & .190 \\
\hline BI5 & .070 & .074 & .653 & .193 & .159 & .165 & .226 & .001 & .229 \\
\hline $\mathrm{BC} 1$ & .135 & .209 & .159 & .078 & .662 & .219 & .114 & -.025 & .089 \\
\hline $\mathrm{BC} 2$ & .170 & .193 & .246 & .094 & .694 & .058 & .160 & -.032 & .213 \\
\hline BC3 & .196 & .147 & .062 & -.021 & .799 & .079 & -.042 & .129 & -.113 \\
\hline $\mathrm{BC} 4$ & .129 & .118 & .093 & .023 & .799 & .068 & .005 & .075 & -.086 \\
\hline SK1 & .059 & .242 & .190 & .043 & .091 & .809 & .040 & -.014 & .052 \\
\hline SK2 & .068 & .312 & .127 & .054 & .198 & .764 & .050 & .034 & -.025 \\
\hline SK3 & .058 & .368 & .101 & -.018 & .105 & .757 & .035 & -.002 & .027 \\
\hline AK1 & .134 & .622 & .207 & .177 & .045 & .227 & .083 & -.065 & .301 \\
\hline $\mathrm{AK} 2$ & .128 & .752 & .099 & .045 & .094 & .126 & -.037 & .056 & -.021 \\
\hline AK3 & .087 & .778 & .136 & .046 & .078 & .119 & -.011 & -.054 & .244 \\
\hline EK1 & .130 & -.381 & -.033 & -.108 & .214 & .246 & .030 & .090 & .623 \\
\hline EK2 & .103 & -.066 & .035 & -.009 & .251 & .212 & .056 & .125 & .691 \\
\hline EK3 & .092 & -.182 & .107 & -.054 & .157 & .219 & .253 & -.021 & .643 \\
\hline
\end{tabular}

Then we use LISREL 8.70 and adopt fixed load method to confirm the factor analysis. Analysis results are shown in Table 3. The load of every item in their respective factor is more than 0.5 , which declares that the scale has good convergent validity. The model fitting is good with $\mathrm{RMSEA}=0.058, \mathrm{NNFI}=0.96, \mathrm{CFI}=0.97$ and AGFI $=0.90$ 
Table 3: Confirmatory Factor Analysis

\begin{tabular}{|c|c|c|c|c|c|c|c|c|}
\hline \multicolumn{8}{|c|}{ Item Component } & \multirow{2}{*}{$\mathbf{T}$} \\
\hline & & 23 & 4 & 5 & $\begin{array}{ll}6 & 7\end{array}$ & $\begin{array}{ll}7 & 8\end{array}$ & 9 & \\
\hline B1 & .75 & & & & & & & --- \\
\hline B2 & .86 & & & & & & & 64.34 \\
\hline B3 & .78 & & & & & & & 56.30 \\
\hline $\mathrm{B} 4$ & & .61 & & & & & & ---- \\
\hline B5 & & .62 & & & & & & 36.05 \\
\hline B6 & & .6 & & & & & & --- \\
\hline B7 & & .7 & & & & & & 49.29 \\
\hline B8 & & .6 & & & & & & 44.86 \\
\hline$\overline{\mathrm{U} 1}$ & & & .59 & & & & & --- \\
\hline U2 & & & .65 & & & & & 44.49 \\
\hline U3 & & & .52 & & & & & 39.89 \\
\hline U4 & & & .67 & & & & & 33.89 \\
\hline U5 & & & .68 & & & & & 45.98 \\
\hline U6 & & & .71 & & & & & 47.41 \\
\hline U7 & & & .55 & & & & & 49.68 \\
\hline U9 & & & .50 & & & & & 32.51 \\
\hline U10 & & & .69 & & & & & 47.74 \\
\hline$\overline{\mathrm{BI} 1}$ & & & & .72 & & & & --- \\
\hline BI2 & & & & .77 & & & & 55.44 \\
\hline BI3 & & & & .71 & & & & 49.72 \\
\hline BI4 & & & & .73 & & & & 51.26 \\
\hline BI5 & & & & .72 & & & & 50.46 \\
\hline$\overline{\mathrm{BC} 1}$ & & & & & .70 & & & --- \\
\hline $\mathrm{BC} 2$ & & & & & .74 & & & 50.84 \\
\hline $\mathrm{BC} 3$ & & & & & .75 & & & 51.71 \\
\hline $\mathrm{BC} 4$ & & & & & .72 & & & 49.12 \\
\hline K1 & & & & & & .79 & & --- \\
\hline K2 & & & & & & .81 & & 59.16 \\
\hline K3 & & & & & & .79 & & 56.79 \\
\hline$\overline{\mathrm{K} 4}$ & & & & & & .70 & & --- \\
\hline K5 & & & & & & .71 & & 48.28 \\
\hline K6 & & & & & & .76 & & 52.42 \\
\hline K7 & & & & & & & .70 & --- \\
\hline K8 & & & & & & & .77 & 54.05 \\
\hline K9 & & & & & & & .72 & 49.82 \\
\hline $\begin{array}{l}\text { Good } \\
\text { Fit }\end{array}$ & Aness & $\begin{array}{r}\text { of }_{9}^{\mathrm{R}} \\
\mathrm{A}\end{array}$ & & $\begin{array}{l}\mathrm{A}=0.0 \\
=0.90, \\
0.90\end{array}$ & 58, NN & $\sqrt{\mathrm{NFI}}$ & & $\mathrm{FI}=0$. \\
\hline
\end{tabular}

(2) Reliability Analysis

Wortzel proposed Cronbach's Alpha Coefficient to test reliability, and argues that the higher the value is, the better the scale is. Table 4 shows the result of the survey. Through the analysis result of SPSS 17.0, Cronbach's alpha coefficients of BGEB is 
0.543(except BGEB), and all the other scales are more than 0.7. This explains that the scale has a good reliability.

Table 4: Reliability Analysis of Data

\begin{tabular}{ll}
\hline Latent Variables & Cronbach's $\boldsymbol{\alpha}$ \\
\hline BEAB & 0.836 \\
BGEB & 0.543 \\
REIB & 0.722 \\
UB & 0.851 \\
BI & 0.849 \\
BC & 0.814 \\
SK & 0.838 \\
AK & 0.764 \\
EK & 0.773 \\
\hline
\end{tabular}

\section{Test of Model and Hypothesis}

According to the concept model, we set initial structure equation model as M. Using LISREL 8.7 for parameter estimation, we modify the model by T test. Normally, chisquare will decrease when we increase the free parameter, and chi-square will increase when we reduce the free parameter. After we increase the free parameter, the Chi-square reduces significantly. This proves that it is worthwhile to increase free parameters. If the free parameters decreases and the chi-square does not significantly increase, it shows that reducing free parameters is acceptable.

The empirical results show that in Model $M$, each path can meet the significant requirements. We delete the path from $\mathrm{AK}$ to $\mathrm{BC}$ and modify model $\mathrm{M}$ to $\mathrm{M} 1$. Its df increases by 1 , and the chi-square increases by 8.95 , larger than 6.63 (as $\alpha=0.01$, the chi-square reaches its critical value). So we don't support the modification of model $\mathrm{M}$ for model M1. We get the same conclusion when we delete the other path. As Table 5 shows, all the Fitting Indexes of the model can meet the requirements, so we choose $\mathrm{M}$ as the final model.

Table 5: Fitting Index of Each Model

M: Initial Model M1: Delete AK to BC path basis on

$\mathrm{M}$

Chi- $\quad 8460.33 \quad 8469.28$

square

df $\quad 540 \quad 541$

$\begin{array}{lll}\text { RMSEA } & 0.060 & 0.060\end{array}$

$\begin{array}{lll}\text { GFI } & 0.94 & 0.94\end{array}$

AGFI $\quad 0.94 \quad 0.93$

$\begin{array}{lll}\text { NNFI } & 0.99 & 0.99\end{array}$

$\begin{array}{lll}\text { CFI } & 0.99 & 0.99\end{array}$ 
Model $\mathrm{M}$ is the optimal model. Results show that all the three types of low carbon related knowledge, namely "system knowledge", "action knowledge" and "effectiveness knowledge", affect low carbon Behavior Intention and competence significantly. The values of direct effect of the three types of knowledge are 0.22 , 0.47 and 0.23 on "Behavior Intention", and are $0.10,0.12$ and 0.37 on "behavior competence". The values of direct effect of "Behavior Intention" on three types of buying behaviors are $0.57,0.36$ and 0.45 , and 0.28 on using behavior. The values of direct effect of "behavior competence" on three types of buying behaviors are -0.02 , 0.23 and 0.13 , and 0.32 on using behavior. Both "Behavior Intention" and "behavior competence" play significant intermediary roles, as all the three types of knowledge indirectly affect the four types of behaviors. Table 6 and Table 7 show the operation results of $\mathrm{M}$.

Table 6 Standardized Path Coefficients and Direct Effect among Variables

\begin{tabular}{lll}
\hline $\begin{array}{l}\text { Variable } \\
\text { Relationship }\end{array}$ & $\begin{array}{l}\text { Standardization } \\
\text { Estimate }\end{array}$ & Direct Effect \\
\hline $\mathrm{SK} \rightarrow \mathrm{BI}$ & 0.24 & 0.22 \\
$\mathrm{AK} \rightarrow \mathrm{BI}$ & 0.46 & 0.47 \\
$\mathrm{EK} \rightarrow \mathrm{BI}$ & 0.22 & 0.23 \\
$\mathrm{BI} \rightarrow \mathrm{BEAB}$ & 0.56 & 0.57 \\
$\mathrm{BI} \rightarrow \mathrm{BGEB}$ & 0.43 & 0.36 \\
$\mathrm{BI} \rightarrow \mathrm{REIB}$ & 0.51 & 0.45 \\
$\mathrm{BI} \rightarrow \mathrm{UB}$ & 0.34 & 0.28 \\
$\mathrm{SK} \rightarrow \mathrm{BC}$ & 0.12 & 0.10 \\
$\mathrm{AK} \rightarrow \mathrm{BC}$ & 0.12 & 0.12 \\
$\mathrm{EK} \rightarrow \mathrm{BC}$ & 0.38 & 0.37 \\
$\mathrm{BC} \rightarrow \mathrm{BEAB}$ & -0.01 & -0.02 \\
$\mathrm{BC} \rightarrow \mathrm{BGEB}$ & 0.27 & 0.23 \\
$\mathrm{BC} \rightarrow \mathrm{REIB}$ & 0.14 & 0.13 \\
$\mathrm{BC} \rightarrow \mathrm{UB}$ & 0.38 & 0.32 \\
\hline
\end{tabular}

Table 7 Indirect Effect among Variables

\begin{tabular}{llll}
$\begin{array}{l}\text { Variable } \\
\text { Relationship }\end{array}$ & Indirect Effect & $\begin{array}{l}\text { Variable } \\
\text { Relationship }\end{array}$ & Indirect Effect \\
\hline $\mathrm{SK} \rightarrow \mathrm{BI} \rightarrow \mathrm{BEAB}$ & $0.22 \times 0.57=0.1254$ & $\mathrm{SK} \rightarrow \mathrm{BC} \rightarrow \mathrm{BEAB}$ & $0.10 \times-0.02=-0.002$ \\
$\mathrm{SK} \rightarrow \mathrm{BI} \rightarrow \mathrm{BGEB}$ & $0.22 \times 0.36=0.0782$ & $\mathrm{SK} \rightarrow \mathrm{BC} \rightarrow \mathrm{BGEB}$ & $0.10 \times 0.23=0.023$ \\
$\mathrm{SK} \rightarrow \mathrm{BI} \rightarrow \mathrm{REIB}$ & $0.22 \times 0.45=0.099$ & $\mathrm{SK} \rightarrow \mathrm{BC} \rightarrow \mathrm{REIB}$ & $0.10 \times 0.13=0.013$ \\
$\mathrm{SK} \rightarrow \mathrm{BI} \rightarrow \mathrm{UB}$ & $0.22 \times 0.28=0.0616$ & $\mathrm{SK} \rightarrow \mathrm{BC} \rightarrow \mathrm{UB}$ & $0.10 \times 0.32=0.032$ \\
$\mathrm{AK} \rightarrow \mathrm{BI} \rightarrow \mathrm{BEAB}$ & $0.47 \times 0.57=0.2679$ & $\mathrm{AK} \rightarrow \mathrm{BC} \rightarrow \mathrm{BEAB}$ & $0.12 \times-0.02=-$ \\
& & & 0.0024 \\
$\mathrm{AK} \rightarrow \mathrm{BI} \rightarrow \mathrm{BGEB}$ & $0.47 \times 0.36=0.1692$ & $\mathrm{AK} \rightarrow \mathrm{BC} \rightarrow \mathrm{BGEB}$ & $0.12 \times 0.23=0.0276$ \\
$\mathrm{AK} \rightarrow \mathrm{BI} \rightarrow \mathrm{REIB}$ & $0.47 \times 0.45=0.2115$ & $\mathrm{AK} \rightarrow \mathrm{BC} \rightarrow \mathrm{REIB}$ & $0.12 \times 0.13=0.0156$ \\
$\mathrm{AK} \rightarrow \mathrm{BI} \rightarrow \mathrm{UB}$ & $0.47 \times 0.28=0.1316$ & $\mathrm{AK} \rightarrow \mathrm{BC} \rightarrow \mathrm{UB}$ & $0.12 \times 0.32=0.0384$ \\
$\mathrm{EK} \rightarrow \mathrm{BI} \rightarrow \mathrm{BEAB}$ & $0.23 \times 0.57=0.1311$ & $\mathrm{EK} \rightarrow \mathrm{BC} \rightarrow \mathrm{BEAB}$ & $0.37 \times-0.02=-$ \\
& & & 0.0074 \\
$\mathrm{EK} \rightarrow \mathrm{BI} \rightarrow \mathrm{BGEB}$ & $0.23 \times 0.36=0.0828$ & $\mathrm{EK} \rightarrow \mathrm{BC} \rightarrow \mathrm{BGEB}$ & $0.37 \times 0.23=0.0851$ \\
$\mathrm{EK} \rightarrow \mathrm{BI} \rightarrow \mathrm{REIB}$ & $0.23 \times 0.45=0.1035$ & $\mathrm{EK} \rightarrow \mathrm{BC} \rightarrow \mathrm{REIB}$ & $0.37 \times 0.13=0.0481$ \\
$\mathrm{EK} \rightarrow \mathrm{BI} \rightarrow \mathrm{UB}$ & $0.23 \times 0.28=0.0644$ & $\mathrm{EK} \rightarrow \mathrm{BC} \rightarrow \mathrm{UB}$ & $0.37 \times 0.32=0.1184$ \\
\hline
\end{tabular}


According to the operation results of the model, we test $\mathrm{H} 1$ and $\mathrm{H} 2$. Results are shown in table 8.

Table 8: Verification of Theory Hypothesis

\begin{tabular}{lll}
\hline Number & Hypothesis & Result \\
\hline H1 & $\begin{array}{l}\text { LCRK may have an indirect and positive effect on } \\
\text { low-carbonized energy consumption behavior through }\end{array}$ & supported \\
& BI & supported \\
H1a & SK may have a direct and positive effect on BI & supported \\
H1b & AK may have a direct and positive effect on BI & supported \\
H1c & EK may have a direct and positive effect on BI & supported \\
H1d & BI may have a direct and positive effect on BEAB & supported \\
H1e & BI may have a direct and positive effect on BGEB & supported \\
H1f & BI may have a direct and positive effect on REIB & supported \\
H1g & BI may have a direct and positive effect on UB & \\
& LCRK may have an indirect and positive effect on & Part \\
H2 & low-carbonized energy consumption behavior through & supported \\
& BC & supported \\
H2a & SK may have a direct and positive effect on BC & supported \\
H2b & AK may have a direct and positive effect on BC & supported \\
H2c & EK may have a direct and positive effect on BC & Not supported \\
H2d & BC may have a direct and positive effect on BEAB & supported \\
H2e & BC may have a direct and positive effect on BGEB & supported \\
H2f & BC may have a direct and positive effect on REIB & supported \\
H2g & BC may have a direct and positive effect on UB &
\end{tabular}

\section{Conclusions}

This empirical study concludes that

(1) System knowledge, action knowledge and effectiveness knowledge have indirect effect on low-cabonized energy consumption behavior through Behavior Intention and behavior competence. Therefore, in order to effectively promote the shift from low carbon knowledge to low carbon behavior, the two key points in designing behavior guidance policy are arousing the residents' low carbon Behavior Intention and the fostering residents' low carbon behavior competence.

(2) Among the three types of Low Carbon Knowledge, the effect of action knowledge is the most positive on Behavior Intention. The value of direct effect is 0.47, more significant than system knowledge on Behavior Intention and effectiveness knowledge on Behavior Intention. The effect of effectiveness knowledge is the most positive on behavior competence. The value of direct effect is 0.37 , more significant than system knowledge on behavior competence and action knowledge on behavior competence.

This suggests that when we convince the residents of Low Carbon Knowledge, we need to bear it in mind that action knowledge about "know how to do" may have more effect on Behavior Intention of the residents, that effectiveness knowledge about "which kind of knowledge is more effective" may have more effect on behavior 
competence of the residents, and that System knowledge about "know what" may have effect on Behavior Intention and behavior competence, but the effect is weaker than that of action knowledge and effectiveness knowledge. Therefore, system knowledge is not the key in promoting Low Carbon Knowledge. In the process of spreading Low Carbon Knowledge, we should be able to distinguish its classifications, and carry out targeted training and promotion. Only in this way can knowledge be effectively transformed into behavior.

(3) Low-cabonized energy consumption behavior is the joint result of Behavior Intention and behavior competence. Through this empirical research, we find that buying behavior is more influenced by low carbon Behavior Intention, and using behavior is more influenced by low carbon behavior competence.

Behavior Intention has a significantly positive effect on the four aspects of "lowcarbonized energy consumption behavior", but the effect on the three buying behaviors is higher than that on using behavior. Behavior competence has a positive effect on the four aspects of "low-carbonized energy consumption behavior" too, but the direction and strength of its influence varies from one behavior to another. Behavior competence has a weak negative effect on buying energy-efficient appliances behavior, and the value of direct effect is -0.02 . This shows that the stronger the urban residents' low carbon behavior competence is, the more negative the buying energy-efficient appliances behavior is. The reason is that people who have strong behavior competence can develop their own energy saving tips. They don't have to rely on the external equipments. Behavior competence has a significantly positive effect on buying green energy behavior, residential energy saving investment behavior and using behavior. Behavior competence has the strongest effect on using behavior and the weakest effect on residential energy saving investment behavior. This shows that in order to guide urban residents' low carbon energy buying behavior, it's important to arouse Behavior Intention, which requires more efforts in promoting action knowledge. Besides, we should pay attention to action knowledge while promoting new Low-carbon product, as it is the major driving force in cultivating buying intention and behavior. In order to guide urban residents' low carbon energy using behavior, it's important to cultivate their behavior competence. This requires more effort in promoting effectiveness knowledge and informing the general public of the more effective ways to reduce $\mathrm{CO} 2$ emissions. In this way they can raise their low carbon behavior competence and develop their habits of low carbon behavior.

\section{Reference}

Ajzen I.(1991) 'The theory of planned behavior'. Organizational Behavior and Human Decision Processes, 4(50): 179-211.

Anna-Lisa Linden, Annika Carlsson-Kanyama, Bjorn Eriksson. (2006) 'Efficient and inefficient aspects of residential energy behaviour: What are the policy instruments for change', Energy Policy, 34: 1918-1927.

Chan R.Y.K.(2001) 'Determinants of Chinese consumers' green purchase behavior '. Psychology \& Marketing, 18(4): 389-413. 
Carmen Tanner, Kast. (2003) 'Promoting Sustainable Consumption: Determinants of Green Purchases by Swiss Consumers’. Psychology \& Marketing., 20(10): 883-902.

Grunert, S. C. (1993) 'Everybody seems concerned about the environment but is this concern reflected in (Danish) consumer food choice', European Advances in Consumer Research, 1: 428-433.

Harland, P., Staats, H., Wilke, H. A. M. (2007) 'Situational and Personality Factors as Direct or Personal Norm Mediated Presictors of Pro-environmental Behavior: Questions Derived from Norm-Activation Theory '. Basic and Applied Social Psychology, 29: 323-334.

Hines, J. M., Hungerford, H. R., \&Tomera, A. N. (1986) 'Analysis and synthesis of research on responsible environmental behavior: A meta-analysis '. Journal of Environmental Education, 18: 1-8.

Jacqueline Frick, Florian G. Kaiser, Mark Wilson. (2004) 'Environmental knowledge and conservation behavior: exploring prevalence and structure in a representative sample '. Personality and Individual Differences, 37(8): 1597-1613.

Kaise F G,Wolfing S, Fuhrer U. (1999) 'Environmental Attitude and Ecological Behavior'. Jounlal of Envirolunental Psvchology, 19: 1-19.

Kara Chen. (1998) 'Mass Communication and Proenvironmental Behavior: Waste Recycling in Hong Kong[J]. Journal of Environmental Management, 52(4): 317- 325.

Khalil Kalalltari, Hossein Shahallali Fami, Alii Asadi. H., MovaHed Mohammadi. (2007) 'Investigatiing Factors Affecting Envirolnmental Behavior of Urban Residents: A Case Study in Tehran City-Iran'. American Journal of Environmental Science,3(2): 67- 74.

Linda Steg, (2008) 'Promoting household energy conservation'. Energy Policy, 36: 44494453.

Lishun Chen. (2009) 'Research on urban residents energy consumption behavior', Doctoral Dissertation, Dalian University of Technology, Dalian,China,

Marcinkowski T. J. (1988) 'An analysis of correlates and predictors of responsible environmental behavior', Doctoral Dissertation,. Southern lllionois University at Carbondate.

Michele T, Paul S P, Margaret P B. (2004) 'Determining pro-environmental behaviour: waste minimisation the drivers for householder compared to recycling '. Resources, Conservation and Recycling, 42: 27-48.

National Bureau of Statistics of the People's Republic of China,( 2010 ),China Energy Satistics Yearbook 2009, China Statistics Press, Beijing

Parker P, Rowlands I, Scott D. (2005) 'Who changes consumption following residential energy evaluations? Local programs need all income groups to achieve Kyoto targets'. Local Environ, 10: 173-187. 
Pieters R.G.M. (1991) 'Changing Garbage disposal patterns of consumers: Motivation, ability, and performance'. Journal of Public Policy \& Marketing, 10(2): 59-76.

Ricky Y K Chan. (2001) 'Determinants of Chinese consumers Green Purchase Behavior'. Psychology \& Marketing , 18(4) : 389-413.

Satoshi F.(2006) 'Environmental concern,attitude toward frugality, and ease of behavior as determinants of pro-environmental behavior intentions '. Journal of Environmental Psvchology, 26: 262-268.

Schahn, J., \&Holzer, E. (1990) 'Studies of individual environmental concern: The role of knowledge, gender and background variables '. Environment and Behavior, 22: 767786.

Scott, D., Parker, P., Rowlands, I. H. (2000) 'Determinants of energy efficiency behaviours in the home '. Environments, 28(3): 73-96.

Simmons, D. \& Widmar, R. (1990) 'Motivations and barriers to recycling: Toward a strategy for public education '. Journal of Environmental Education, 22: 13-18.

Staats.H, Van Leeuwen.E, Wit. A. P, (2000) 'A longitudinal study of informational interventions to save energy in an office building'. Journal of Applied Behavior Analysis, 33: 101-104.

Stephen P Robbins. (1997) Organizational Behavior, China Renmin University Press \&PREVTICE Hall Press, 72-73.

Stern P.C. (1992) 'What psychology knows about energy conservation'. American Psychology, 47: 1224-1232.

Stern P.C, Dietz T., Abel T., Guagnano. G.A., Kalof L. (1999) 'A value-belief-norm theory of support for social movements: The case of environmentalism '. Research in Human Ecology, 6(2): 81-97.

Stewart Barr, Andrew W Gilg, Nicholas Ford. (2005) 'The household energy gap: examining the divide between habitual and purchase-related conservation behaviours'. Energy Policy, 33: 1425-1444.

The Ministry of Science and Technology of the People's Republic of China, (2007), 'National energy conservation and emission reduction in manual', http://www.most.gov.cn/ztzl/jqinjp/qmjnjpsc/qmjnjpsc-qy.htm

The State Council of the People's Republic of China, (2007) 'Notice on the strict implementation of public buildings air conditioning temperature control standard' State Council, 2007 (42)

Thomas LWebb, Paschal Sheeran. (2006) 'Does Changing Behavioral Intentions Engender Behavior Change? A Meta-Analysis of the Experimental Evidence', Psychological Bulletin, 132(2), 249-268

Van Diepen A. (2000). 'Households arid Their Spatial-energetic Practices.Searching for Sustainable Urban forms '. Doctoral Dissertation, University of Groningen, the Netherlands 
Van Raaij, Th. Verhallen T. (1983) 'A behavioral model of residential energy use '. Journal of Economic Psychology, 3(1): 39-63.

Xianfeng. Zhang (2010) Low Carbon Life Knowledge Reader Hubei Science and Technology Press, Wuhan China

Yan Sun (2006) 'Research on residential environment behavior and its influencing factors', Doctoral Dissertation, Dalian University of Technology, Dalian,China,

Zhi Yang, Danping Liu (2010) Open the Window of Low Carbon Economy. Economic management press, Beijing China 